\title{
A Prospective Observational Multicenter Study of Balloon Angioplasty for the Treatment of Native and Recurrent Coarctation of the Aorta
}

\author{
Kevin C. Harris, ${ }^{1} \mathrm{MD}$, Wei Du, ${ }^{2}$ PHD, Collin G. Cowley, ${ }^{3} \mathrm{MD}$, Thomas J. Forbes, ${ }^{2} \mathrm{MD}$, and \\ Dennis W. Kim, ${ }^{4 *}$ MD, PHD; On Behalf of the Congenital Cardiac Intervention Study \\ Consortium (CCISC)
}

\begin{abstract}
Objectives: Balloon angioplasty (BA) is an important treatment option for coarctation of the aorta. The congenital cardiovascular interventional study consortium (CCISC) represents a multi-institutional and multi-national effort to prospectively investigate congenital cardiac interventions. A prospective observational analysis of the efficacy and safety of balloon aortic angioplasty was conducted. Methods: Data were collected prospectively from $36 \mathrm{CCISC}$ sites from 2004 to 2012 . One hundred and thirty patients underwent BA for native $(n=76)$ and recurrent $(n=54)$ coarctation. Acute, short-term, and intermediate outcomes are described for BA performed in the setting of native and recurrent coarctation of the aorta. Outcome measures included residual upper to lower extremity blood pressure gradient (ULG), use of antihypertensive medications, aortic wall injury, reobstruction, and need for reintervention. Results: There was no procedural mortality. Acutely in native and recurrent coarctation, BA achieved an ULG less than $15 \mathrm{~mm} \mathrm{Hg}$ in $73-80 \%$ and to less than $10 \mathrm{~mm} \mathrm{Hg}$ in $54-68 \%$ of patients, respectively. At intermediate follow-up, ULG further improved, particularly for those who underwent initial reintervention for recurrent coarctation. No significant differences in aortic wall complications were seen and intervention free survival was similar for both groups. Following angioplasty, there was no significant difference in aortic wall complications; however follow up integrated imaging decreased over time. Conclusions: BA is a safe and effective treatment for coarctation of the aorta acutely and at intermediate term. Although aortic injury occurred in patients with both native and recurrent coarctation, at intermediate follow-up, aneurysm was noted more often in those with initial intervention for native coarctation. 2013 Wiley Periodicals, Inc.
\end{abstract}

Key words: coarctation; angioplasty; congenital heart disease

\section{INTRODUCTION}

Coarctation of the aorta may be found as an isolated lesion or may be associated with other congenital heart abnormalities. The incidence of coarctation of the aorta is approximately $1 / 3000$ to $1 / 4000$ [1]. The most common defect associated with coarctation of the aorta is a bicuspid aortic valve, though this may not necessarily cause hemodynamically significant valvular stenosis.

\footnotetext{
${ }^{1}$ Department of Pediatrics, BC Children's Hospital, Vancouver, British Columbia, Canada

${ }^{2}$ Department of Pediatrics, Children's Hospital of Michigan, Wayne State University, Detroit, Michigan

${ }^{3}$ Department of Pediatrics, Primary Children's Hospital, University of Utah, Salt Lake City, Utah

${ }^{4}$ Department of Pediatrics, Children's Healthcare of Atlanta,

Emory University, Atlanta, Georgia
}

Conflict of interest: Nothing to report.
*Correspondence to: Dennis W. Kim, MD, PhD; Sibley Heart Center Cardiology, Children's Healthcare of Atlanta, 2835 Brandywine Rd, Suite 300, Atlanta, GA 30341. E-mail: kimd@kidsheart.com

Received 23 April 2013; Revision accepted 4 November 2013

DOI: $10.1002 / \mathrm{ccd} .25284$

Published online 8 November 2013 in Wiley Online Library (wileyonlinelibrary.com) 
TABLE I. Inclusion and Exclusion Criteria

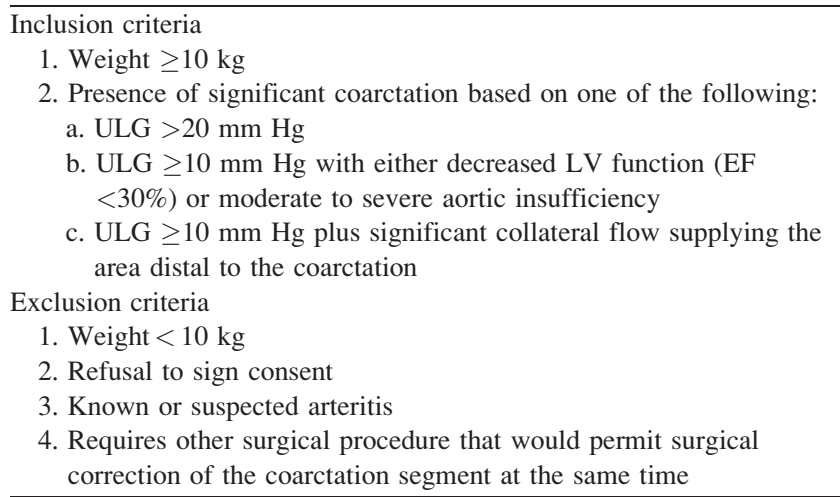

$\mathrm{kg}$, kilogram; ULG, upper to lower extremity systolic blood pressure gradient; LV, left ventricle; EF, ejection fraction.

Unrepaired coarctation of the aorta is associated with significant morbidity and mortality, with approximately $90 \%$ mortality observed by age 50 [2]. The aorta in patients with coarctation of the aorta is abnormal due to histologic differences in the smooth muscle and extracellular matrix, which may affect local compliance and distensibility [3,4]. These differences may affect the tissue response to catheter-based interventions and long-term outcomes including risk for systemic hypertension and aneurysm formation.

Current therapeutic options include surgery, intravascular stent placement, and balloon angioplasty (BA). Catheter-based therapies have demonstrated comparable efficacy to surgery in children greater than 1 year of age $[5,6]$. Outside of rescue situations or if surgical options are limited, balloon aortic angioplasty has been less embraced for neonates and young infants due to concern for the high incidence of recurrent stenosis [7]. With all forms of therapy, repeat intervention may be required due to restenosis or aneurysm formation, which typically occurs at the coarctation site or adjacent areas. There are varying reports regarding the relative complication rates of surgery compared to BA $[5,8]$. BA may be complicated by aneurysm formation; however the true risk of aneurysm formation is unknown with estimates ranging from 8 to $35 \%$ [810]. Most studies are retrospective, single institution studies with relatively few patients, which may contribute to the divergent results. Furthermore, the historical measure of procedural success (residual upper to lower extremity blood pressure gradient (ULG) $\leq 20 \mathrm{~mm} \mathrm{Hg}$ ) is largely an arbitrary convention [11,12]. Given that continuing morbidities such as systemic hypertension can affect patients after repair/intervention with minimal residual blood pressure gradient [13-15], it is conceivable that the standard for immediate procedural success should be referenced to a lower gradient postprocedure.
To better understand the efficacy and safety of BA for the treatment of native and recurrent coarctation of the aorta, we performed a prospective multicenter evaluation of the acute to intermediate-term results.

\section{METHODS \\ Study Population and Design}

This prospective multi-institutional observational study involved 36 centers in the congenital cardiovascular interventional study consortium (CCISC). A complete list of participating centers may be found in the online appendix. Inclusion and exclusion criteria are listed in Table I. Institutional review board approvals were locally obtained by each participating center. Patients were defined as having native coarctation if they did not have any previous surgical or catheterbased intervention. Recurrent coarctation was defined as coarctation occurring after previous surgery or BA at study entry. Case report form completion for the initial angioplasty, reintervention, short term (3-18 months), and intermediate follow up (18-60 months) was supervised by the participating physician and entered into a secure CCISC database. Integrated imaging including computed tomography (CT), magnetic resonance imaging $(\mathrm{MRI})$, or cardiac catheterization was performed at each of the follow up intervals. Initial, follow up and reintervention imaging studies were reviewed by core laboratory physicians. These data are a focused and expanded extension of that reported by Forbes et al. [6], comparing surgery, stent therapy, and BA in the treatment of native coarctation of the aorta. The decision to pursue BA instead of alternate therapy was left to the discretion of the individual physicians.

\section{Data Collection}

Preintervention data. Patient demographics including age, weight, gender, and associated diagnoses were documented. Baseline clinical information including upper and lower extremity systolic and diastolic blood pressure (BP), antihypertensive medications, preintervention measurements of the long axis of the aorta (CT, MRI, or catheterization), and coarctation type/ location were documented.

Procedural data. Preprocedural gradient was measured by direct catheter pullback from the ascending to descending aorta. A distal transverse aortic arch BP measurement was recorded to assess potential transverse aortic arch obstruction. Biplane angiography was performed in the anteroposterior or left anterior oblique and lateral views. Dimensions of the transverse aorta, coarctation segment, area distal to the coarctation, and abdominal aorta at the level of the diaphragm

Catheterization and Cardiovascular Interventions DOI 10.1002/ccd. Published on behalf of The Society for Cardiovascular Angiography and Interventions (SCAI). 
were obtained. The balloon type, size, and length were documented. Postprocedural gradient and angiographic measurements were repeated in a similar fashion.

Discharge data. Upper and lower extremity BP, complications before discharge, length of hospital stay, and antihypertensive medication use were documented. The decision to initiate or continue antihypertensive therapy was at the discretion of institutional preference.

Follow-up data. Imaging studies (MRI, CT, or angiography) were performed at short and intermediateterm follow-up as described above. Patient demographics, upper and lower extremity $\mathrm{BP}$, and antihypertensive medications were recorded at the time of follow-up evaluation.

Reintervention data. Reintervention was performed for recurrent stenosis, as part of a staged dilation strategy, and due to the development of aneurysm formation. Hemodynamic and angiographic data were collected in the same fashion as that at the time of the original BA.

\section{Definition of Coarctation/Transverse Aortic Arch Anatomy}

Proximal coarctation was defined as a coarctation segment located $\leq 10 \mathrm{~mm}$ from the origin of the left subclavian artery, with distal coarctation defined as a coarctation segment located $>10 \mathrm{~mm}$ from the origin of the left subclavian artery. Hypoplastic transverse aortic arch (TAA) was defined as a ratio of the TAA to descending aorta measured at the level of the diaphragm $<0.6$. Aneurysm was defined as a diameter $>20 \%$ than the adjacent descending aorta (DAo) that is not considered to be poststenotic dilation of the aorta, or an abnormal localized enlargement of the aortic segment in the area of intervention.

\section{Outcome Assessments}

Hemodynamic outcome. Systolic BP gradient measured from upper to lower extremities (ULG) at the time of discharge, follow-up, and reintervention were used as the primary hemodynamic outcomes. These outcomes were dichotomized using 10 and 15 $\mathrm{mm} \mathrm{Hg} \mathrm{ULG} \mathrm{as} \mathrm{cut-offs.} \mathrm{The} \mathrm{systolic} \mathrm{gradient} \mathrm{meas-}$ ured at coarctation site directly by catheter (ascending to descending aorta) pre- and postintervention was recorded.

Angiographic outcome. The coarctation repair site dimension was compared to the aortic diameter at the level of the diaphragm (Coarctation: DAo). Follow-up outcomes were assessed by MRI, CT, or angiographic measurements of the coarctation repair site.

\section{Safety Endpoint}

Safety endpoints were death, aortic wall injury, other procedural complications, and unanticipated reintervention acutely, at short-term, and at intermediate follow-up.

\section{Reobstruction}

Reobstruction of the coarctation angioplasty site by imaging was categorized as mild $(<10 \%$ narrowing of vessel lumen), moderate (11-30\% narrowing), or severe ( $>30 \%$ narrowing). However, the decision for reintervention was not strictly dependent on the grading of reobstruction by non-invasive imaging studies. The indication for and decision to pursue reintervention was not predefined by the CCISC. This decision was based on the comprehensive assessment of the individual operator with residual hemodynamic gradient taken into consideration.

\section{Postinterventional Hypertension}

Postinterventional hypertension was defined as a persistent systolic BP $\geq 95$ th percentile for height and weight lasting $>48 \mathrm{hr}$ after the initial intervention.

\section{Core Laboratory Assessment}

All imaging data were reviewed at one of four core laboratory centers: Nationwide Children's Hospital, Columbus, Ohio; National Children's Medical Center, Washington, D.C.; University of Texas Southwestern Medical Center, Dallas, Texas; and Penn State University, Hershey, Pennsylvania.

\section{Statistical Methods}

To compare patient baseline and outcome characteristics among patient groups, student's $t$-test and chisquare tests (or Fisher's exact) were used. Kaplan-Meier product limit actuarial curves and log-rank tests were used to compare reintervention-free survival duration from the time of the first procedure. Subgroup analysis comparing children $\leq 12$ years in the entire cohort with those $>12$ years were performed to assess the effect of age on patient outcomes. Furthermore, we compared outcomes in children $\geq 7$ years with native coarctation to those $<7$ years with native coarctation to determine the safety and efficacy of this procedure in younger children. A $P$-value $<0.05$ was considered statistically significant, and SAS 9.3 was used for all analyses.

\section{RESULTS}

Between February 1, 2002, and October 31, 2012, 130 children from 36 institutions underwent BA for 
TABLE II. Baseline Characteristics

\begin{tabular}{lccc}
\hline Patient characteristics & $\begin{array}{c}\text { Native } \\
n=76\end{array}$ & $\begin{array}{c}\text { Recurrent } \\
N=54\end{array}$ & $\begin{array}{c}P \\
\text { (two-sided) }\end{array}$ \\
\hline Age (years; mean \pm SD) & $8.0 \pm 7.5$ & $13.8 \pm 10.3$ & $<0.001$ \\
Weight (kg; mean \pm SD) & $26.9 \pm 19.4$ & $44.9 \pm 22.5$ & $<0.001$ \\
Male (vs. Female \%) & $48(63 \%)$ & $33(61 \%)$ & 0.85 \\
Preprocedure right-arm & $135 \pm 23$ & $128 \pm 17$ & 0.04 \\
$\quad$ systolic blood pressure & & & \\
$\quad$ (mm Hg; mean \pm SD) & & & \\
Preprocedure ULG & $41 \pm 3$ & $21 \pm 18$ & $<0.001$ \\
$\quad$ (mean \pm SD) & & & \\
Coarctation Location (\%) & & & \\
$\quad$ Isthmus & $95 \%$ & $77 \%$ & \\
$\quad$ Distal & $66 \%$ & $32 \%$ & \\
$\quad$ Proximal & $28 \%$ & $45 \%$ & \\
$\quad$ Transverse aorta & $3 \%$ & $15 \%$ & \\
$\quad$ Abdominal/thoracic aorta & $1 \%$ & $0 \%$ & \\
$\quad$ Complex & $1 \%$ & $8 \%$ & \\
Single ventricle & $0 \%$ & $6 \%$ & 0.07 \\
Shone syndrome & $0 \%$ & $6 \%$ & 0.07 \\
Bicuspid aortic valve (\%) & $47 \%$ & $44 \%$ & 0.86 \\
\hline
\end{tabular}

$\mathrm{SD}$, standard deviation; ULG, upper to lower extremity systolic blood pressure gradient.

coarctation of the aorta. Of those, 76 underwent BA for native coarctation and 54 for recurrent coarctation.

\section{Baseline Characteristics}

As expected, children undergoing BA for recurrent coarctation were older $(P<0.001)$ and weighed more than children with native coarctation $(P<0.001$; Table II). The preprocedure ULG was higher in children with native coarctation. Native coarctation was almost always located in the isthmic area past the takeoff of the left subclavian artery, whereas, recurrent coarctation was located in the transverse arch in $15 \%$ of cases. Recurrent coarctation in the transverse arch also was seen in children undergoing primary surgical repair. In those with recurrent coarctation, the primary therapy was angioplasty in 26\% $(n=14)$ and surgery in $74 \%$ $(n=40)$. As expected, native and recurrent coarctation were both associated with a bicuspid aortic valve in approximately half of the cases.

\section{Acute Outcomes}

Hemodynamic outcomes were assessed by measuring the preintervention and discharge ULG noninvasively. In both groups, angioplasty significantly reduced the ULG from preintervention to time of discharge (Table III). The discharge ULG was lower in children with recurrent coarctation. Notably, approximately $3 / 4$ of patients in both groups had an ULG $\leq 15 \mathrm{~mm} \mathrm{Hg}$ after angioplasty. The majority of patients in both groups (54\% native, $68 \%$ recurrent) also met the criteria for $\mathrm{ULG} \leq 10 \mathrm{~mm} \mathrm{Hg}$ at the time of discharge.
There were no deaths in either group. The rate of aortic wall injury was low (11\% native, $7 \%$ recurrent) predominantly due to intimal tear or dissection. There was one aneurysm noted acutely $(<1 \%)$ in a patient undergoing BA for recurrent coarctation. There was one balloon rupture without significant sequelae in each group and one femoral hematoma in the recurrent coarctation group. The length of hospital stay post-BA was similar for native and recurrent coarctation.

\section{Short-Term Outcomes}

Short-term follow-up was available for 45 patients with native coarctation and 30 patients with recurrent coarctation, representing 59 and $56 \%$ of the initial cohorts, respectively. At short-term follow-up, approximately $3 / 4$ of patients has normal systolic blood pressure (SBP) (Table IV) with antihypertensive use of $16 \%$ in the native coarctation group and $30 \%$ in the recurrent coarctation group (this difference did not achieve statistical significance, however). Mean ULG remained low at less than $10 \mathrm{~mm} \mathrm{Hg}$. When compared to acute outcomes at residual ULG cutoffs at $\leq 10 \mathrm{~mm}$ $\mathrm{Hg}$, patients undergoing angioplasty for both native and recurrent coarctation maintained a similar result as noted at the time of the procedure. Available integrated imaging follow-up was similar for both groups $(73 \%$ native, $80 \%$ recurrent). There was a larger vessel caliber at the site of coarctation for those undergoing angioplasty due to recurrent obstruction compared to those with native coarctation (coarctation to descending aorta ratio of 0.75 and 0.88 in native and recurrent coarctation, respectively, $P=0.03$ ). Reobstruction as assessed by imaging was noted in $22 \%$ of patients with native coarctation and was most often mild. Reobstruction was rare in patients with recurrent coarctation (7\%). Continuing aortic wall injury was noted in $27 \%$ of imaged patients with native coarctation of the aorta (20\% patients with short-term follow-up). Aortic aneurysms were noted by integrated imaging in seven patients $(21 \%$ of imaged patients, $16 \%$ with short-term follow-up) with native coarctation and in two patients (8\% of imaged patients, $7 \%$ with short-term follow-up) those with recurrent coarctation. There were no interstage deaths.

\section{Intermediate-Term Outcomes}

Intermediate-term follow-up was available for 34 patients with native coarctation 27 patients with recurrent coarctation, representing 45 and $50 \%$ of the initial cohorts, respectively. At intermediate-term follow-up, $68 \%$ of patients with native coarctation and $88 \%$ of patients with recurrent coarctation had normal SBP (Table V). The rate of antihypertensive therapy was

Catheterization and Cardiovascular Interventions DOI 10.1002/ccd. Published on behalf of The Society for Cardiovascular Angiography and Interventions (SCAI). 
TABLE III. Acute Outcomes

\begin{tabular}{lccc}
\hline Patient characteristics & $\begin{array}{c}\text { Native } \\
n=76\end{array}$ & $\begin{array}{c}\text { Recurrent } \\
N=54\end{array}$ & $\begin{array}{c}P \\
\text { (two-sided) }\end{array}$ \\
\hline Discharge ULG (Mean \pm SD) & $9 \pm 14$ & $3 \pm 16$ & 0.02 \\
Discharge ULG $\leq 10 \mathrm{~mm} \mathrm{Hg} \mathrm{( \% )}$ & $54 \%$ & $68 \%$ & 0.19 \\
Discharge ULG $\leq 15 \mathrm{~mm} \mathrm{Hg} \mathrm{( \% )}$ & $73 \%$ & $80 \%$ & 0.40 \\
Any complications (\#, \%) & $9(12 \%)$ & $7(13 \%)$ & 0.81 \\
Aortic wall complications (\#, \%) & $8(11 \%)$ & $5(7 \%)$ & 0.55 \\
$\quad$ Aneurysm (\#) & 0 & 1 & \\
$\quad$ Dissection (\#) & 3 & 2 & \\
$\quad$ Intimal tear (\#) & 5 & 2 & \\
Balloon rupture (\#) & 1 & 1 & 0.32 \\
Femoral hematoma (\#) & 0 & 1 & \\
Length of stay in days & & & \\
$\quad$ mean \pm SD) & $2.9 \pm 9.0$ & $1.7 \pm 4.3$ &
\end{tabular}

ULG, upper to lower extremity systolic blood pressure gradient; SD, standard deviation.

TABLE IV. Short-Term Follow-Up

\begin{tabular}{lccc}
\hline Clinical follow-up outcomes & $\begin{array}{c}\text { Native } \\
n=45\end{array}$ & $\begin{array}{c}\text { Recurrent } \\
N=30\end{array}$ & $P$ (two-sided) \\
\hline Normal systolic blood pressure & $78 \%$ & $72 \%$ & 0.60 \\
Antihypertensive medication & $16 \%$ & $30 \%$ & 0.14 \\
ULG (Mean \pm SD) & $8 \pm 18$ & $0 \pm 22$ & 0.11 \\
ULG $\leq 10 \mathrm{~mm}$ Hg & $43 \%$ & $67 \%$ & 0.05 \\
ULG $\leq 15 \mathrm{~mm} \mathrm{Hg}$ & $68 \%$ & $74 \%$ & 0.56 \\
\hline Integrated imaging & $n=33$ & $n=24$ & \\
$\quad$ follow-up outcomes & & & \\
Any complications & $16(48 \%)$ & $5(21 \%)$ & 0.03 \\
$\quad$ \#, \% imaged subgroup) & $9(27 \%)$ & $2(8 \%)$ & 0.07 \\
Aortic wall injury & & & \\
$\quad$ \#, \% imaged subgroup) & 2 & 0 & \\
$\quad$ Dissection/intimal tear (\#) & 7 & 2 & \\
$\quad$ Aneurysm (\#) & & & \\
Coarctation: Descending Aortic & $0.75 \pm 0.22$ & $0.88 \pm 0.21$ & 0.03 \\
$\quad$ ratio (mean \pm SD) & & 3 & 0.20 \\
Any reobstruction (\#) & 11 & 2 & \\
$\quad$ Mild (\#) & 6 & 1 & \\
$\quad$ Moderate (\#) & 1 & 0 & \\
Severe (\#) & 4 &
\end{tabular}

ULG, upper to lower extremity systolic blood pressure gradient; SD, standard deviation.

slightly lower than at short-term follow-up with only $12 \%$ use in the native coarctation group and $30 \%$ use in the recurrent coarctation group, suggesting an ability to wean from antihypertensive medications for many. The ULG remained lower in those with recurrent coarctation compared to native coarctation, as was seen acutely and at short-term follow-up, suggestive of ongoing vascular remodeling. The ULG was $\leq 15 \mathrm{~mm}$ $\mathrm{Hg}$ in $94 \%$ of those with recurrent coarctation and $73 \%$ of those with native coarctation. ULG was $\leq 10$ $\mathrm{mm} \mathrm{Hg}$ in $94 \%$ treated for recurrent coarctation and $60 \%$ for those with native coarctation. Integrated imaging was available for $62 \%$ of native and $67 \%$ of recurrent patients. Imaging outcomes demonstrated a similar Catheterization and Cardiovascular Interventions DOI 10.1002/ccd.

Published on behalf of The Society for Cardiovascular Angiography and Interventions (SCAI).
TABLE V. Intermediate-Term Follow-Up

\begin{tabular}{lccc}
\hline Clinical follow-up outcomes & $\begin{array}{c}\text { Native } \\
n=34\end{array}$ & $\begin{array}{c}\text { Recurrent } \\
N=27\end{array}$ & $\begin{array}{c}P \\
\text { (two-sided) }\end{array}$ \\
\hline Normal systolic blood pressure & $68 \%$ & $88 \%$ & 0.06 \\
Antihypertensive medication & $12 \%$ & $30 \%$ & 0.08 \\
ULG (mean \pm SD) & $4 \pm 17$ & $-13 \pm 18$ & $<0.01$ \\
ULG $\leq 10 \mathrm{~mm} \mathrm{Hg}$ & $60 \%$ & $94 \%$ & 0.04 \\
ULG $\leq 15$ mm Hg & $73 \%$ & $94 \%$ & 0.12 \\
\hline $\begin{array}{l}\text { Integrated imaging follow-up } \\
\text { outcomes }\end{array}$ & $n=21$ & $n=18$ & \\
Any complications & $12(57 \%)$ & $6(33 \%)$ & 0.20 \\
$\quad$ \#, \% imaged subgroup) & & & \\
Aortic wall injury & $9(43 \%)$ & $3(17 \%)$ & 0.17 \\
$\quad$ \#, \% imaged subgroup) & & & \\
$\quad$ Dissection/intimal tear (\#) & 1 & 1 & \\
$\quad$ Aneurysm (\#) & 8 & 2 & \\
Coarctation: Descending Aortic & $0.77 \pm 0.12$ & $0.78 \pm 0.18$ & 0.92 \\
$\quad$ ratio (mean \pm SD) & & & \\
Any reobstruction (\#) & 5 & 4 & 0.13 \\
$\quad$ Mild (\#) & 5 & 1 & \\
Moderate (\#) & 0 & 1 & \\
Severe (\#) & 0 & 2 & \\
\hline
\end{tabular}

ULG, upper to lower extremity systolic blood pressure gradient; SD, standard deviation.

coarctation to descending aorta ratio in both native and recurrent coarctation $(0.77$ and 0.78$)$. At intermediateterm follow-up, reobstruction as assessed by integrated imaging was seen in $24 \%$ of patients $(15 \%$ of all with intermediate follow-up) with native coarctation and $22 \%$ of patients ( $15 \%$ of all with intermediate follow-up) in the recurrent coarctation group. Reobstruction was described as mild in all patients in the native coarctation group. Two of four patients in the recurrent group had reobstruction described as severe. There were two aortic aneurysms seen in the recurrent coarctation group (11\% with imaging, $7 \%$ of all with intermediate follow up) and eight aneurysms in patients with native coarctation at intermediate-term follow-up (38\% with imaging, 24\% of all with intermediate follow-up).

\section{Time to Reintervention}

Thirteen patients underwent reintervention (eight native coarctation and five recurrent coarctation). The need for reintervention was determined by the interventional cardiologist performing the procedure without predetermined criteria established by the CCISC. The most common indication for reintervention was moderate to severe reobstruction (12/13). There was one case of reintervention due to aortic wall injury initially detected at short-term follow-up, which occurred after BA for native coarctation. The overall reintervention free survival probability was approximately $95 \%$ at 1 year and $85 \%$ at 10 years. There was no significant difference in reintervention rates between native and recurrent coarctation (Fig. 1). 


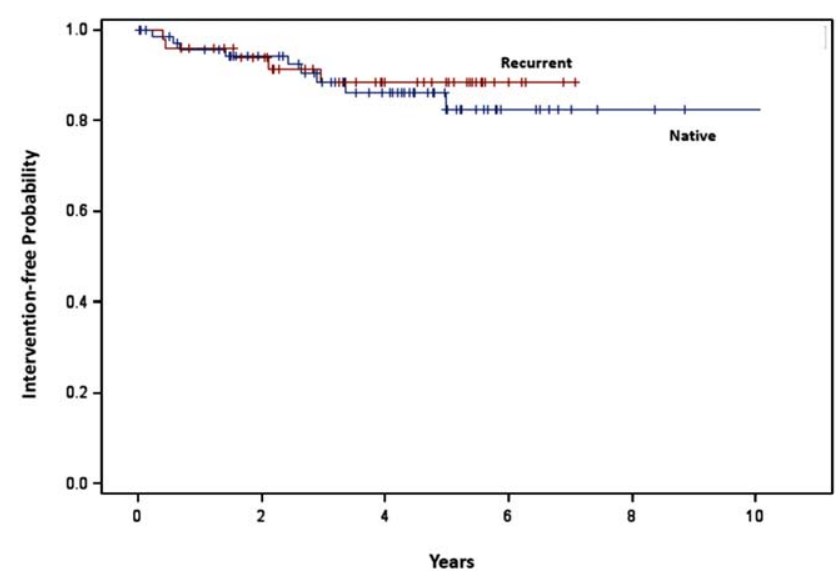

Fig. 1. Intervention-free survival in native and recurrent coarctation. [Color figure can be viewed in the online issue, which is available at wileyonlinelibrary.com.]

\section{Subgroup Analysis by Age}

Subgroup analysis was performed to assess the effect of age on the results. Because entry into the teenage/adolescent years represents a time period where coarctation stenting has generally been considered acceptable, we assessed those $\leq 12$ years in the overall population compared to those $>12$ years. As BA may be favored in younger children over primary stenting, we also assessed the safety and efficacy of BA for native coarctation in children $<7$ years compared to those $\geq 7$ years to determine the acute efficacy, short-term and intermediate-term follow-up, and complications. The most striking finding from the subgroup analysis was that children $<7$ years with native coarctation have similar rates of acute complications and aortic wall injury at short- and intermediate-term follow-up. There was a trend toward fewer young children achieving an ULG $\leq 10 \mathrm{~mm} \mathrm{Hg}$ (45\% in those $<7$ years compared to $67 \%$ in those $\geq 7$ years). However, $73 \%$ of children $<7$ years had an ULG $\leq 15 \mathrm{~mm} \mathrm{Hg}$ acutely, which was identical to the rate seen in children $\geq 7$ years. In the overall cohort there were no significant differences in measures of success or complication rates between those $>12$ years and those $\leq 12$ years. No other statistically significant differences were noted.

\section{DISCUSSION}

Native and recurrent aortic coarctations are both amenable to catheter-based intervention. Our results confirm that native and recurrent coarctation respond differently to BA. The reduction in the coarctation gradient was greater for patients with recurrent coarctation both acutely and through intermediate-term follow-up based on non-invasive BP measurements. In the recurrent coarctation group at intermediate-term follow-up,
$87 \%$ had an $\mathrm{ULG}<10 \mathrm{~mm} \mathrm{Hg}$ and $94 \%<15 \mathrm{~mm} \mathrm{Hg}$ indicating that the effectiveness of this therapy is sustained over time. Our results compare favorably with previously published data [16,17], although, notably our definition of recurrent coarctation included patients who had previous surgical repair or BA before study enrollment. The historically accepted definition of success after BA has been a final gradient $<20 \mathrm{~mm} \mathrm{Hg}$. As catheter-based therapies and surgical techniques have matured, this definition of success may require re-evaluation. We present data at cut points of $15 \mathrm{~mm}$ $\mathrm{Hg}$ and $10 \mathrm{~mm} \mathrm{Hg} \mathrm{BP} \mathrm{gradients.} \mathrm{Importantly,} \mathrm{a} \mathrm{trend}$ of decreasing ULG over time was observed during follow-up suggestive of ongoing remodeling in the aorta following BA.

Native coarctation may be successfully treated with $\mathrm{BA}$; however, these data show that it is more frequently associated with reobstruction, which is most often mild. The recent report from the CCISC demonstrated superior hemodynamic results with stent placement and surgery compared to BA [6]. Furthermore, there was a lower complication rate with stent placement compared to BA alone. As such, the current trend seems to be shifting toward primary stent placement in older children and adults while surgery remains favored in young children $[18,19]$. BA as a bridge to stent therapy may be an effective alternative to surgery for young children who are too small to initially accommodate a stent that can be serially dilated to adult size. The comparable safety of BA in children less than 7 years old in our study population would support this approach.

Persistent hypertension is known to be a continuing morbidity following treatment of coarctation in up to half of patients [20]. In our cohort, the use of antihypertensive therapy declined from short-term to intermediate-term follow-up in children with native coarctation (16-12\%). This is consistent with the expected resolution of hypertension over time after improvement in aortic obstruction. Some patients will have hypertension that persists and may contribute to long-term morbidity [20,21]. Notably, the overall use of antihypertensive therapy at intermediate follow-up was lower in children under 12 years of age $(3 \%)$ than those over 12 years $(30 \%)$. Although this may be in part due to age related differences in the tissue recovery and remodeling process, we hypothesize there may be a bias toward withholding antihypertensive medications in young children compared to older children. In addition, under recognition of hypertension in patients after treatment for coarctation of the aorta may partially explain this observation [22].

Complications seen in the setting of BA may include aortic wall injury characterized by intimal tear, vascular dissection, aneurysm formation, femoral hematoma

Catheterization and Cardiovascular Interventions DOI 10.1002/ccd Published on behalf of The Society for Cardiovascular Angiography and Interventions (SCAI). 
at the entry site, and neurologic complications. There were no neurologic complications in either group. There was one femoral hematoma $(<1 \%)$. The rate of angiographically identifiable acute aortic wall injury was similar in both groups at approximately $10 \%$. The rate of aneurysm formation increased over time. At intermediate follow-up there was a higher rate of aortic wall irregularity in the native coarctation group although this difference was not statistically significant. The overall aneurysm rate at intermediate follow-up was $26 \%$ with eight of ten aneurysms seen in the native coarctation group. Spontaneous improvement in aneurysm size was seen over time in two patients undergoing BA for recurrent coarctation, whereas three new aneurysms were noted in patients with native coarctation. Given these low numbers, we can only speculate whether this is reflective of how mechanical manipulation by BA affects the substrate involving recurrent coarctation compared to native coarctation. The progression of aortic wall injury over time requires further investigation given its important implications in determining how to manage these complications. The rate of aneurysm formation seen in this study is similar to previous reports where aneurysms were seen in up to $35 \%$ of patients [8]. In studies limited to older adolescents and adults, the rate of aneurysm formation is considerably lower [23,24]. However, there may be a bias in obtaining integrated imaging follow-up after angioplasty for aortic coarctation, with less additional imaging occurring in patients for whom there is less clinical concern for aneurysm formation. Follow-up integrated imaging at intermediate-term was suboptimal with 39 of the original 130 patients continuing to receive additional imaging. There was notable attrition from intake through to intermediate follow-up with fewer children undergoing integrated imaging than clinical follow-up. Some attrition was due to the time interval between the intervention and the specified follow-up, as some of the children who have undergone intervention have not yet reached the specified follow-up periods. In addition, there was some loss to follow-up and adherence to recommend integrated imaging scheduling was incomplete. A more complete understanding of the relationship between aortic coarctation interventions and the natural history of aortic wall injury requires more knowledge of the coarctation substrate, before and after intervention. A more detailed characterization of aortic pathology, beyond the designation of recurrent vs. native coarctation, is likely needed. This may be possible with more in depth knowledge of structural vessel wall changes, vascular properties, and cellular components in the affected area of the aorta.

Reintervention-free survival was similar in native and recurrent coarctation despite the finding that ULG was different in these groups postintervention. It is possible that the higher ULG in native coarctation may be due to more frequent mild obstruction that does not necessitate reintervention. Alternatively, the similar reintervention rates despite discrepant ULG may be due to a lack of predefined criteria for reintervention. A third possibility is that the sample size was too small to detect a difference in reintervention rates given the relatively small number of patients that had extended follow-up. Nonetheless, the overall reintervention-free survival was $>90 \%$ at 1 year and $>80 \%$ at 5 and 10 years. It is important to note that while this demonstrates excellent results in a broad population of children and young adults with coarctation, children $<10$ $\mathrm{kg}$ were excluded in this study. As such, we have excluded children who underwent BA for recurrent coarctation in the setting of a recent Norwood procedure, which is known to have higher reintervention rates [25].

The strengths of this study are that it includes a large number of patients from multiple centers. The patients were followed for up to 10 years. As with all registries, the main limitation this consortium faced was difficulty obtaining complete follow-up data, particularly integrated imaging. The choice of the type of follow-up imaging was left to physician discretion and there is some possibility that there could be some difference in dimensional measurements, although imaging was reviewed at core laboratory centers. Finally, the indications for reintervention were not predetermined and there remains considerable variability in the pattern of practice with regard to deciding when to reintervene. We did further stratify outcomes to cut points of $\leq 15 \mathrm{~mm} \mathrm{Hg}$ and $\leq 10 \mathrm{~mm} \mathrm{Hg}$, which continued to show good hemodynamic results, particularly for those undergoing angioplasty for recurrent coarctation.

\section{CONCLUSIONS}

In summary, BA can be an effective strategy for treatment of coarctation of the aorta outside of infancy. It is a safe and highly effective therapy for recurrent coarctation of the aorta. Native coarctation treated with BA results in reduced coarctation gradients, although there is a trend toward recurrence of mild obstruction. Both native and recurrent coarctations have excellent reintervention-free survival through intermediate-term follow-up after BA. The historic arbitrary hemodynamic cutoff by which success following BA was defined $(\leq 20 \mathrm{~mm} \mathrm{Hg})$ may be inadequate in the current era. At additional criteria of residual gradient $\leq 15$ $\mathrm{mm} \mathrm{Hg}$ and $\leq 10 \mathrm{~mm} \mathrm{Hg}$, BA continues to be an effective therapy, particularly for those treated for recurrent

Catheterization and Cardiovascular Interventions DOI 10.1002/ccd.

Published on behalf of The Society for Cardiovascular Angiography and Interventions (SCAI). 
obstruction. Aneurysm formation remains a concern after any treatment for coarctation of the aorta, particularly BA for native coarctation, although further treatment of these aneurysms is rare in the intermediate term. Further research is needed to find the optimal balance between relief of aortic obstruction and minimizing the risk of aneurysm formation to optimize long-term health outcomes for patients with coarctation of the aorta.

\section{REFERENCES}

1. Fixler DE, Pastor P, Chamberlin M, Sigman E, Eifler CW. Trends in congenital heart disease in Dallas County births. 1971-1984. Circulation 1990;81:137-142.

2. Campbell M. Natural history of coarctation of the aorta. Brit Heart J 1970;32:633-640.

3. Vogt M, Kuhn A, Baumgartner D, Baumgartner C, Busch R, Kostolny M, et al. Impaired elastic properties of the ascending aorta in newborns before and early after successful coarctation repair: Proof of a systemic vascular disease of the prestenotic arteries? Circulation 2005;111:3269-3273.

4. Jimenez M, Daret D, Choussat A, Bonnet J. Immunohistological and ultrastructural analysis of the intimal thickening in coarctation of human aorta. Cardiovasc Res 1999;41:737-745.

5. Rodes-Cabau J, Miro J, Dancea A, Ibrahim R, Piette E, Lapierre $\mathrm{C}$, et al. Comparison of surgical and transcatheter treatment for native coarctation of the aorta in patients $>$ or $=1$ year old. The Quebec Native Coarctation of the Aorta study. Am Heart J 2007;154:186-192.

6. Forbes TJ, Kim DW, Du W, Turner DR, Holzer R, Amin Z, et al. Comparison of surgical, stent, and balloon angioplasty treatment of native coarctation of the aorta: An observational study by the CCISC (Congenital Cardiovascular Interventional Study Consortium). J Am Coll Cardiol 2011;58:2664-2674.

7. Hornung TS, Benson LN, McLaughlin PR. Interventions for aortic coarctation. Cardiol Rev 2002;10:139-148.

8. Cowley CG, Orsmond GS, Feola P, McQuillan L, Shaddy RE. Long-term, randomized comparison of balloon angioplasty and surgery for native coarctation of the aorta in childhood. Circulation 2005; 111:3453-3456.

9. Fawzy ME, Fathala A, Osman A, Badr A, Mostafa MA, Mohamed G, et al. Twenty-two years of follow-up results of balloon angioplasty for discreet native coarctation of the aorta in adolescents and adults. Am Heart J 2008;156:910-917.

10. Tanous D, Benson LN, Horlick EM. Coarctation of the aorta: Evaluation and management. Curr Opin Cardiol 2009;24:509-515.

11. Walhout RJ, Lekkerkerker JC, Oron GH, Bennink GB, Meijboom EJ. Comparison of surgical repair with balloon angioplasty for native coarctation in patients from 3 months to 16 years of age. Eur J Cardiothorac Surg 2004;25:722-727.

12. Hernandez-Gonzalez M, Solorio S, Conde-Carmona I, RangelAbundis A, Ledesma M, Munayer J, et al. Intraluminal aortoplasty vs. surgical aortic resection in congenital aortic coarctation.
A clinical random study in pediatric patients. Arch Med Res 2003;34:305-310.

13. Instebo A, Norgard G, Helgheim V, Roksund OD, Segadal L, Greve G. Exercise capacity in young adults with hypertension and systolic blood pressure difference between right arm and leg after repair of coarctation of the aorta. Eur J Appl Physiol 2004;93:116-123.

14. Vriend JW, van Montfrans GA, Romkes HH, Vliegen HW, Veen G, Tijssen JG, et al. Relation between exercise-induced hypertension and sustained hypertension in adult patients after successful repair of aortic coarctation. J Hypertens 2004;22: 501-509.

15. Bald M, Neudorf U. Arterial hypertension in children and adolescents after surgical repair of aortic coarctation defined by ambulatory blood pressure monitoring. Blood Press Monit 2000;5: $163-167$.

16. Hijazi ZM, Fahey JT, Kleinman CS, Hellenbrand WE. Balloon angioplasty for recurrent coarctation of aorta. Immediate and long-term results. Circulation 1991;84:1150-1156.

17. Yetman AT, Nykanen D, McCrindle BW, Sunnegardh J, Adatia I, Freedom RM, et al. Balloon angioplasty of recurrent coarctation: A 12-year review. J Am Coll Cardiol 1997;30:811-816.

18. Fruh S, Knirsch W, Dodge-Khatami A, Dave H, Pretre R, Kretschmar O. Comparison of surgical and interventional therapy of native and recurrent aortic coarctation regarding different age groups during childhood. Eur J Cardiothorac Surg 2011;39: 898-904.

19. McGuinness JG, Elhassan Y, Lee SY, Nolke L, Oslizlok P, Walsh K, et al. Do high-risk infants have a poorer outcome from primary repair of coarctation? Analysis of 192 infants over 20 years. Ann Thorac Surg 2010;90:2023-2027.

20. Brown ML, Burkhart HM, Connolly HM, Dearani JA, Hagler DJ, Schaff HV. Late outcomes of reintervention on the descending aorta after repair of aortic coarctation. Circulation 2010; 122(Suppl 11):S81-4.

21. Pedersen TA, Munk K, Andersen NH, Lundorf E, Pedersen EB, Hjortdal VE, et al. High long-term morbidity in repaired aortic coarctation: Weak association with residual arch obstruction. Congenit Heart Dis 2011;6:573-582.

22. Gillett C, Wong A, Wilson DG, Wolf AR, Martin RP, Kenny D. Underrecognition of elevated blood pressure readings in children after early repair of coarctation of the aorta. Pediatr Cardiol 2011;32:202-205.

23. Walhout RJ, Suttorp MJ, Mackaij GJ, Ernst JM, Plokker HW. Long-term outcome after balloon angioplasty of coarctation of the aorta in adolescents and adults: Is aneurysm formation an issue? Catheter Cardiovasc Interv 2009;73:549-556.

24. Fawzy ME, Awad M, Hassan W, Al Kadhi Y, Shoukri M, Fadley F. Long-term outcome (up to 15 years) of balloon angioplasty of discrete native coarctation of the aorta in adolescents and adults. J Am Coll Cardiol 2004;43:1062-1067.

25. Porras D, Brown DW, Marshall AC, Del Nido P, Bacha EA, McElhinney DB. Factors associated with subsequent arch reintervention after initial balloon aortoplasty in patients with Norwood procedure and arch obstruction. J Am Coll Cardiol 2011; $58: 868-876$ 